\title{
Comparison of Student Performance and Perceptions Across Multiple Course Delivery Modes
}

\section{Dr. Matthew Cavalli, University of North Dakota}

Dr. Cavalli is an Associate Professor and Department Chair of the Mechanical Engineering Department at the University of North Dakota. In addition to engineering education, his research interests include materials behavior and solid mechanics.

\section{Dr. Jeremiah J. Neubert, University of North Dakota}

Mr. Dustin McNally, University of North Dakota

Dustin McNally is a Senior Lecturer in Mechanical Engineering at the University of North Dakota. Dustin received a Bachelor's of Science in both Mechanical Engineering and International Studies as well as a Master's of Science in Mechanical Engineering, all from the University of North Dakota.

Debbie Jacklitch-Kuiken 


\title{
Comparison of Student Performance and Perceptions Across Multiple Course Delivery Modes
}

\begin{abstract}
The concept of the flipped class has received a great deal of attention in recent years. In a flipped class, students are expected to view lecture material prior to the class period so that time with the instructor can be spent on higher level problem solving and discussions. Previous work has shown the potential for both deeper learning and extended content coverage using the flipped instructional model. This study aims to gage the effect of the flipped pedagogy implemented with learning aids primarily consisting of short, on-line videos. Comparisons of student learning between the different cohorts were made with the use of pre- and post-tests as well as other assessment mechanisms during the course of the semester. In addition, all students were surveyed at the end of the semester to understand their perceptions of the pedagogy used and provide them an opportunity to offer suggestions. Advantages and limitations of the traditional and flipped course structure are discussed with suggestions for potential improvements.
\end{abstract}

\section{Introduction}

In a traditional classroom, an instructor will typically introduce new material during class-time through lecture/demonstration or the use of a more active pedagogy. Active learning can be defined as, 'any instructional method that engages students in the learning process,' and examples include problem-based learning and collaborative/cooperative learning ${ }^{1}$. These active pedagogies have been found to be effective tools for maximizing student learning and keeping them engaged. The most significant obstacle to using these techniques is the loss of lecture time resulting in a loss in the amount of material that can be covered in class.

This issue can be addressed by adopting a flipped or inverted classroom pedagogy. In the flipped classroom, students are required to learn new material prior to coming to class ${ }^{2,3}$. Learning aids are typically prepared by the instructor and can include videos, tutorials, texts, etc. ${ }^{4}$. Class-time is then spent on active learning activities that focus on knowledge integration and application ${ }^{4}$. Swartz et al. ${ }^{5}$ notes that implementation of a flipped classroom is not an all-ornothing proposition - it is possible to flip a portion of a class while retaining other teaching methods throughout. This partial approach was also endorsed by Rockland et al. ${ }^{6}$, particularly with respect to the amount of instructor time required to effectively flip an entire course.

Learning aids for a flipped course vary, but there is general agreement that they must be short and concise ${ }^{2-12}$. Students must be informed which materials are needed to be prepared for the classroom activities. In addition, best practices dictate that there must be a "gate" - assessment to ensure that students arrive to class properly prepared. Unprepared students will have trouble participating in the active learning exercises leading to frustration. The use of in-class minilectures prior to the in-class activities can reduce the impact on those arriving unprepared, as 
well as providing the instructor with a mechanism to highlight important concepts. Additionally, the mini-lecture gives students an opportunity to ask questions on the material covered in the learning aids prior to attempting the classroom activity.

It is important to note some research has shown that the flipped pedagogy is not ideal for achieving lower-level learning outcomes such as knowledge and comprehension ${ }^{10}$. Other studies have shown potentially significant gains for flipped learners ${ }^{12}$. When higher-level learning outcomes such as analysis and synthesis are evaluated, a properly flipped course often demonstrates significant gains over traditional course design ${ }^{10}$. Thus it is critical that any comparison between flipped and non-flipped courses carefully select the points of comparison.

\section{Motivation}

The University of North Dakota is the only institution to offer accredited Bachelor of Science degrees in Mechanical, Chemical, Civil, Electrical, and Petroleum engineering at a distance. Currently, at-a-distance students simply watch recorded lectures asynchronously and complete the same assessments as the on-campus students. The College of Engineering is looking to improve the learning experience for both on-campus and at-a-distance students through the adoption of the flipped classroom pedagogy across the curriculum. The college would like to leverage the existing Tegrity lecture recording system to produce the required learning aids.

The proposed implementation of flipped teaching has raised questions about the effect of such a change on both the on-campus and at-a-distance students. Specifically, will the on-campus students benefit from the video lecture material-learning aids_-and will the distance students benefit from the in-class activities. Moreover, are the benefits a function of the course level?

\section{Method}

During the Fall 2013 semester, four courses were selected to evaluate the flipped delivery mode for both on-campus and at-a-distance learners in comparison with a more traditional course structure. A list of the courses selected for the study and their corresponding enrollment can be found in Table 1. These courses included an introductory mechanical engineering design course (ME 101), an introductory engineering mechanics course (ENGR 201), a computer programming/numerical methods course (ENGR 200), and a junior-level materials science course (ME 301). All courses included both on-campus and at-a-distance learners. ENGR 200 and ME 301 had both flipped and traditional sections of the course on campus, as well as a flipped format distance section. Only one instructor was used for each course to allow comparisons to be made between the sections without having to control for the effects different instructors may have on student performance.

Data collected from each course included student assessment results and an end-of-course, online survey. The survey was optional and anonymous. Students were sent an email with a link. They were asked to click on the link and answer the survey questions. Participants could answer as many questions as they wished and quit at any time without penalty.

In addition, pre- and post-tests were used to evaluate the impact of the pedagogy on student knowledge. The tests were course-specific and only used in the ENGR 201 and ME 301 courses. 
These tests were created to measure student ability at a variety of knowledge levels from recall to analysis.

Table 1: Classes involved with the current study

\begin{tabular}{|l||ll|l|r|}
\hline Course & Offered & \multicolumn{1}{l|}{ Pedagogy } & \multicolumn{1}{c|}{ Students } & Enrollment \\
\hline \hline \multirow{2}{*}{ ME 101 } & Fall 2013 & Traditional & Campus & 34 \\
& Fall 2013 & Flipped & Dist. & 35 \\
\hline ENGR 200 & Fall 2013 & Traditional & Campus & 33 \\
& Fall 2013 & Flipped & Campus & 32 \\
& Fall 2013 & Flipped & Dist. & 20 \\
\hline \multirow{2}{*}{ ENGR 201 } & Fall 2013 & Traditional & Campus & 59 \\
& Fall 2013 & Flipped & Dist. & 25 \\
\hline \multirow{2}{*}{ ME 301 } & Fall 2013 & Traditional & Campus & 35 \\
& Fall 2013 & Flipped & Campus & 38 \\
& Fall 2013 & Flipped & Dist. & 27 \\
\hline
\end{tabular}

\section{Course Objective}

ME 101

The objective of this course is to produce students that can

- Proficiently use a contemporary 3D drafting program to model existing mechanisms as well as create new ones,

- Follow the engineering design process to create a new mechanism to meet specific engineering criteria, and

- Work in groups to solve complex problems.

Objectives are achieved using a series of demonstrations followed by hands-on activities that require students to utilize a specific set of tools in the drafting software over the first ten weeks of the course. The remaining time is dedicated to an open-ended project that requires groups of students to design a mechanism to solve an engineering problem. The problem includes a set of constraints that must be navigated to be successful. Students are also asked to produce the part drawings needed to construct the mechanism and use the drawings to create a prototype.

ENGR 200

The objective of this course is to produce students that can:

- Create software to solve engineering problems using both C and MATLAB, and

- Apply a systematic procedure to solve complex engineering problems. 
The objectives are accomplished through a series lectures/discussions coupled with handouts on specific aspects of programming syntax and format. The lectures utilize small group activities followed with a short discussion to ensure that students stay actively involved. These lectures/discussions are followed by hands-on programming exercises where students apply concepts learned in lecture to solve engineering problems.

\section{ENGR 201}

The objective of this course is to produce students that can:

- Create accurate free body diagrams,

- Generate the equations of motion from the diagrams, and

- Solve the problems using a vector-based approach.

Objectives are achieved through the use of short lectures to present theory, techniques, and commonly used equations followed by demonstrations to illustrate there use in solving real world problems. Students are then asked to work in small groups as the instructor guides them through the problem solving process with a variety of example exercises.

ME 301

The objective of this course is to produce students that can:

- Link macroscopic material behavior to microscopic phenomena,

- Explain fundamental differences between classes of materials (metals and polymers, for example) and what causes them, and

- Predict general material behavior given information about the microstructure, chemical composition, etc.

Course objectives in ME 301 are achieved by approaching material behavior in four segments: general atomics structure/bonding, mechanical properties, electrical/magnetic/optical properties, and thermal properties. Class sessions in the traditional format are spent in a combination of lecture, discussion, and group-work. Students in both the traditional and flipped sections are expected to complete a reading quiz related to material presented in the textbook.

\section{Course Structure}

The courses followed the traditional semester-based format. Their duration was 16 weeks and the classes met for 150 minutes each week. Assessment of student attainment of the learning objectives was done using a mix of problem-based assignments, quizzes, and exams.

\section{Traditional}

The traditional lecture sections were taught using a combination of lecture and active learning exercises. The active learning exercises were limited to allow all the required lecture material to be covered. Videos were not available to students taking a traditional course. 


\section{Flipped}

In the flipped sections several short videos were made available prior to class time. Each video focused on a single topic and was typically less than 15 minutes in duration. Students were expected to watch the videos prior to class time. Short online quizzes were used as a "gate" to encourage proper student preparation. Class time was then dedicated to higher level learning activities. A mini-lecture was used to provide students with some basic background and instructions for the activity. For the on-campus sections using the flipped format, students worked in small groups to complete the exercises. Afterward, the instructor led the students in a discussion of the methodology used to complete each exercise.

The at-a-distance students were provided as similar an experience as possible. They were able to view a recording of the mini-lecture. At the end of the mini-lecture the instructor would ask them to pause the video and complete the exercise. This was followed by a recording of the inclass discussion in the case of ENGR 200 or a discussion board of similar topics in ME 301. Because no such discussion was available for ME 101 and ENGR 201, the instructor presented a discussion of the solution making sure to highlight important points and common student misconceptions.

\section{Results}

\section{ME 101}

There were two sections of ME 101: one on-campus section and another at-a-distance section. The later was taught using an inverted format. In the traditional, on-campus section $91 \%$ of the students that completed the course received a $\mathrm{C}$ or better. This compared to only $68 \%$ of the students in the flipped section obtaining a $\mathrm{C}$ or better. The flipped section also had a significantly lower percentage of students completing the course. A summary of these results is shown in Table 2. This can likely be attributed to differences in student population (anecdotally, at-a-distance students have family commitments and a full-time job). Additionally, when there is not a specific class time, students must have exceptional time management skills or they quickly fall behind. This conclusion is supported by historical completion rates of approximately $65 \%$.

Table 2: The grade distribution of ME 101. The first column reflects the percentage of students that do not have to retake the course, students that obtained an A, B, or C. The second column contains the percentage of students that took the final exam, but must retake the course. The final column indicated the percentage of students that withdrew or stopped participating in the course prior to the final.

\begin{tabular}{l|cc|c|} 
& \multicolumn{1}{c}{$\mathrm{A} / \mathrm{B} / \mathrm{C}$} & $\mathrm{D} / \mathrm{F}$ & \multicolumn{1}{c}{$\mathrm{W} / \mathrm{NF}$} \\
\cline { 2 - 4 } Flipped at-a-distance & $68 \%$ & $0 \%$ & $32 \%$ \\
\cline { 2 - 4 } Traditional on-campus & $91 \%$ & $3 \%$ & $6 \%$ \\
\cline { 2 - 3 } & &
\end{tabular}


As with the ME 101 course, the ENGR 201 consisted of two sections: one on-campus section with a traditional format and the other at-a-distance in the flipped format. Table 3 shows that student achievement in both sections was nearly identical. This was rather surprising when compared with the results in Tables 2, 4 and 5. Because this instructor had not taught this course in prior years there was no historical data to put these results in perspective. Thus, it is difficult to determine if the nearly identical performance by the at-a-distance and on-campus students is due to the flipped format or the instructor.

Table 3: The grade distribution of ENGR 201. The format is identical to that of Table 2.

\begin{tabular}{l|cc|c|}
\multicolumn{1}{c}{} & \multicolumn{1}{c}{$\mathrm{A} / \mathrm{B} / \mathrm{C}$} & $\mathrm{D} / \mathrm{F}$ & \multicolumn{1}{c}{$\mathrm{W} / \mathrm{NF}$} \\
\cline { 2 - 5 } Flipped at-a-distance & $80 \%$ & $12 \%$ & $8 \%$ \\
\cline { 2 - 4 } Traditional on-campus & $80 \%$ & $15 \%$ & $5 \%$ \\
\cline { 2 - 4 } & &
\end{tabular}

The grade distribution is a reasonable mechanism for measuring student achievement, but it does not capture student learning - the amount the student learned in the course. An exam issued at the beginning and end of the course was used to gage how much the students "learned" independent of differences in student preparedness. The average pre-test score for the at-adistance learners, $52.2 \%$, was slightly lower than that of their on-campus peers, $57.2 \%$. Despite this difference, the at-a-distance students performed better on the post-test with an average score of $94.8 \%$ compared to the on-campus average of $86.2 \%$. The average improvement in the test score was $50 \%$ greater for the at-a-distance learners. This data indicates that the flipped format allowed at-a-distance students to close the knowledge gap between the two populations allowing them to perform nearly identically to their on-campus cohort in the assessments.

\section{ENGR 200}

There were three sections of the ENGR 200 course: two on-campus sections and one at-adistance section. The at-a-distance section and one of the on-campus sections were taught using the flipped format. This allowed for one of the on-campus sections to be used as a control so that the impact of the flipped format could be measured more accurately. Table 4 shows the grade distribution for each section. The students in the traditional section had the best performance with $82 \%$ passing, $10 \%$ better than the flipped format on-campus section. In addition, $6 \%$ of the students in the flipped format, on-campus course completed it with a failing grade, while every student that completed the traditional course was able to achieve a passing grade.

Table 4: The grade distribution of ENGR 200. The format of the table is identical to that of Table 2.

\begin{tabular}{l|cc|c|}
\multicolumn{1}{c}{} & \multicolumn{1}{c}{$\mathrm{A} / \mathrm{B} / \mathrm{C}$} & $\mathrm{D} / \mathrm{F}$ & \multicolumn{1}{c}{$\mathrm{W} / \mathrm{NF}$} \\
\cline { 2 - 4 } Flipped on-campus & $72 \%$ & $6 \%$ & $22 \%$ \\
\cline { 2 - 4 } Flipped at-a-distance & $55 \%$ & $10 \%$ & $35 \%$ \\
\cline { 2 - 4 } Traditional on-campus & $82 \%$ & $0 \%$ & $18 \%$ \\
\cline { 2 - 4 } & &
\end{tabular}


As with ME 101, the grade distribution of the at-a-distance section was troubling with only 55\% of the students successfully completing the class. Again, this was similar to historical averages indicating that the flipped format did not have a significant impact on student success in the course.

\section{ME 301}

There were also three sections of ME 301 used in the study. One on-campus section was taught using the traditional pedagogy, while the remaining sections used the flipped format. The data in Table 5 indicates that the students in ME 301 benefitted from the flipped format. Only 5\% of the on-campus students in the flipped course did not successfully complete it. Moreover, everyone that completed the flipped course obtained a passing grade. Again, the data reveals that the at-adistance learners have a significantly lower rate of success. This is a little surprising in that $\mathrm{ME}$ 301 is a junior-level course with experienced students that should have the study habits and time management skills needed to succeed. Particularly worrisome is the $23 \%$ of at-a-distance students that completed the course without obtaining a passing grade.

Table 5: The grade distribution of ME 301. While the format is identical to that of Table 2, students receiving a D in the course were not required to retake it, the table format was maintained to allow for easier comparison.

\begin{tabular}{l|cc|c|} 
& \multicolumn{1}{c}{$\mathrm{A} / \mathrm{B} / \mathrm{C}$} & $\mathrm{D} / \mathrm{F}$ & \multicolumn{1}{c}{$\mathrm{W} / \mathrm{NF}$} \\
\cline { 2 - 4 } Flipped on-campus & $95 \%$ & $0 \%$ & $5 \%$ \\
\cline { 2 - 4 } Flipped at-a-distance & $68 \%$ & $23 \%$ & $9 \%$ \\
\cline { 2 - 4 } Traditional on-campus & $87 \%$ & $8 \%$ & $5 \%$ \\
\cline { 2 - 4 } & &
\end{tabular}

The benefits of the flipped format on student learning could also be seen on the pre- and post-test data. The average pre-test score for the at-a-distance students was highest on the pre-test, $44.6 \%$. Conversely, those students in the flipped format, on-campus section had the lowest average score, 39.4\%. The average pre-test score for the traditional formatted, on-campus section was $42.4 \%$. The post-test score for the at-a-distance and on-campus, flipped format sections were $60.4 \%$ and $58.6 \%$, respectively, while the traditional section post-test score was $55.5 \%$. This was interesting because the improvement in the test scores for flipped format sections was significantly higher than that of the traditional, on-campus section. These results confirm our initial findings in ENGR 201: student learning in the flipped format courses is greater than that in traditional courses.

\section{Survey Results}

The students in the study were surveyed about their learning experience. The survey asked those students in the flipped sections about their preference for flipped format courses on a scale of 1 to 5 with 1 being strongly prefer the flipped format and 5 representing a strong preference for the traditional format. The survey results are summarized in Table 6 . They show that majority of students prefer the flipped format. Distance students show a stronger preference with an average score of 2.0, while the on-campus students gave a slightly lower preference with a score of 2.6. This is likely due to the fact that distance students expect to view online videos as part of the 
learning process. The new videos represent an improved version of this-short, concise, subjectspecific videos that are easier to watch than 50 minute lectures. In contrast, on-campus students are accustomed to attending live lectures where they can interact with the instructor. The on-line video represents a significant change in their learning experience. It should also be noted that informal discussions with students that were struggling in the flipped format, on-campus courses indicated that they did not like watching videos. In fact, there was some resentment that the instructor would not give such lectures live so they could ask questions.

Table 6: Summary of the results from the survey given to the students.

\begin{tabular}{l|c|c|c|c|c|}
\multicolumn{4}{c}{} & \multicolumn{2}{c}{ Flipped Format } \\
\cline { 2 - 6 } & $\begin{array}{c}\text { 1-strongly } \\
\text { prefer }\end{array}$ & 2-prefer & 3-neutral & 4-prefer & $\begin{array}{c}\text { 5-strongly } \\
\text { prefer }\end{array}$ \\
\cline { 2 - 6 } $\begin{array}{l}\text { At-a-distance } \\
\text { On-campus }\end{array}$ & 22 & 17 & 11 & 3 & 2 \\
\cline { 2 - 6 } & 6 & 20 & 10 & 9 & 3 \\
\hline
\end{tabular}

\section{Discussion}

The results of this study were interesting. Students in the lower level courses either did not benefit from the flipped pedagogy (ME 101/ENGR 200) or showed limited gains (ENGR 201). The data collected in ME 101 and ENGR 200 indicates that student performance may actually be adversely affected the flipped format. The data collected in ENGR 200 indicated that student performance in the flipped on-campus section was worse than that in the traditional, on-campus course. In the ENGR 201 course, a sophomore level engineering course, student performance in the flipped and traditional sections was similar, but the pre- and post-testing indicated that more learning took place with the students in the flipped section. In the junior level course, the data indicates that students benefited from the flipped format course.

These results may be explained by student experience. To succeed in engineering students must become independent, self-regulated learners. Anecdotal evidence gathered from students that struggled with the flipped format indicated that they failed to make time to watch the lectures despite the "gates" used to encourage students to come to class prepared. These students not only missed out on the material in the video, but were unlikely to get the full benefit of the inclass exercises.

It is also possible that the results may improve with subsequent offerings as the instructors gain more experiences with flipped format courses. For example, small changes to the course could be used to address some of the issues that can lead to less than optimal student learning. This includes taking the time to emphasize the importance of watching the videos and experimenting with the "gates" to find a way to ensure students come to class prepared to participate in the activities. Specifically, the creation of gates that encourages student continue to invest time in learning the material until they pass the gate.

Lastly, some thought must be given to the small, but important group of students that are put-off by the flipped format as implemented in this study. It may be that recorded lectures are not the ideal learning aid. Alternatives include interactive online content and reading material. This 
eliminates the perception by some students that professors are not providing them with the access required to be successful.

\section{Summary}

This paper explores the effects of the flipped pedagogy on student achievement of educational objectives and the learning experience. It compares students in the flipped class to those in a control group taught using a traditional methodology. In addition, the paper looks into the effect of this flipped pedagogy on at-a-distance learners. The data on student learning with the flipped pedagogy was mixed. In fact, the data showed that the flipped pedagogy had no effect or was detrimental to student achievement some lower level courses (ME 101 and ENGR 200). Students in ENGR 201 and ME 301 seemed to benefit from the flipped format. Student surveys showed that most students enjoyed the flipped format with distance students strongly preferring it.

\section{References}

1. Prince, M. (2004). "Does Active Learning Work? A Review of the Research." Journal of Engineering Education 93(3): 223-231.

2. Bishop, J. L. and M. A. Verleger (2013). The Flipped Classroom: A Survey of the Research. ASEE Annual Conference and Exposition, Atlanta, GA, ASEE.

3. Lage, M. J., G. J. Platt, et al. (2000). "Inverting the Classroom: A Gateway to Creating an Inclusive Learning Environment." Journal of Economic Education 31(1): 30-43.

4. Hamdan, N., P. McKnight, et al. (2013). A Review of Flipped Learning, Flipped Learning Network.

5. Swartz, B., S. B. Velegol, et al. (2013). Three Approaches to Flipping CE Courses: Faculty Perspectives and Suggestions. ASEE Annual Conference and Exposition, Atlanta, GA, ASEE.

6. Rockland, R., L. Hirsch, et al. (2013). Learning Outside the Classroom - Flipping an Undergraduate Circuits Analysis Course. ASEE Annual Conference and Exposition, Atlanta, GA, ASEE.

7. McClelland, C. J. (2013). Flipping a Large-Enrollment Fluid Mechanics Course - Is It Effective? ASEE Annual Conference and Exposition, Atlanta, GA, ASEE.

8. Connor, K. A., D. L. Newman, et al. (2013). Self-Regulated Learning and Blended Technology Instruction in a Flipped Classrom. ASEE Annual Conference and Exposition, Atlanta, GA, ASEE.

9. Zappe, S., R. Leicht, et al. (2009). "Flipping" The Classroom to Explore Active Learning in a Large Undergraduate Course. ASEE Annual Conference and Exposition, Louisville, KY, ASEE.

10. Redekopp, M. W. and G. Ragusa (2013). Evaluating Flipped Classroom Strategies and Tools for Computer Engineering. ASEE Annual Conference and Exposition, Atlanta, GA, ASEE.

11. Morin, B., K. M. Kecskemety, et al. (2013). The Inverted Classroom in a First-Year Engineering Course. ASEE Annual Conference and Exposition, Atlanta, GA, ASEE.

12. Mason, G., T. R. Shuman, et al. (2013). Inverting (Flipping) Classrooms - Advantages and Challenges. ASEE Annual Conference and Exposition, Atlanta, GA, ASEE. 